\title{
DEGRADATION OF POLYCAPROLACTONE ELECTROSPUN MATERIALS - METHODS OF ANALYSIS
}

\author{
${ }^{1}$ Kristýna HAVLÍČKOVÁ, ${ }^{2}$ Michal ŘEZANKA, ${ }^{3}$ Libor KOBERA, ${ }^{1}$ Eva KUŽELOVÁ KOŠŤÁKOVÁ, \\ ${ }^{1}$ David LUKÁŠ, ${ }^{1}$ Věra JENČOVÁ \\ ${ }^{1}$ Technical University of Liberec, Faculty of Science, Humanities and Education, Departmnt of Chemistry, \\ Liberec, Czech Republic, EU, kristyna.havlickova@tul.cz \\ ${ }^{2}$ Technical University of Liberec, Institute for Nanomaterials, Advanced Technology and Innovation, \\ Department of Nanochemistry, Liberec, Czech Republic, EU, michal.rezanka@tul.cz \\ ${ }^{3}$ Institute of Macromolecular Chemistry CAS, Czech Academy of Sciences, Prague, Czech Republic, EU, \\ kobera@imc.cas.cz
}

https://doi.org/10.37904/nanocon.2021.4354

\begin{abstract}
Biodegradable electrospun materials are widely used for medical application. Polycaprolatone is polymer suitable for electrospinning technology and is very often used to create nanofibrous scaffolds for tissue engineering. The time to disintegration or biodegradation of such materials is very important here. However, testing is not entirely easy. It is not possible to create exactly body-like conditions in vitro. Moreover, it is not easy to find suitable analytical methods that would show exactly what happens in the nanofibrous polycaprolactone electrospun samples at certain stages of degradation, ie how the internal structure of decaying nanofibers changes. This paper describes the traditional use of methods for testing polycaprolatone nanofibers by enzymatically catalysed degradation. Morphological changes are studied using scanning electron microscope images. However, it also offers a non-traditional analysis of polycaprolactone electrospun materials using the ssNMR method.
\end{abstract}

Keywords: Electrospinning, nanofibers, enzymatic degradation, solid state NMR

\section{INTRODUCTION}

Polymeric materials are the most widely used building units for the production of biocompatible materials for medical applications. In the last three decades, the attention in the area of polymer synthesis focused on the theme of biodegradable and biocompatible polymers. Much attention is paid in literature to the preparation of nanofibers from polycaprolactone (PCL) [1-4]. The polymer is semicrystalline linear aliphatic polyester that is biocompatible and biodegradable. PCL has outstanding physical-chemical properties (glass transition temperature $-60{ }^{\circ} \mathrm{C}$; melting temperature $60{ }^{\circ} \mathrm{C}$, temperature of most rapid crystallization $30{ }^{\circ} \mathrm{C}$ ), solubility and sensitivity to biodegradation.

The production of polymer nanofibers can be ensured by several different technologies such as melt blown, centrifugal spinning, flash spinning, air-jet spinning, drawing, etc. [5,6]. One of the most used technologies for the production of polymer nanofibers is electrospinning. Electrospinning is used mainly with a DC power supply, but it is also possible to use AC power supplies [7,8]. The DC needle-less continuous electrospinning produces homogeneous nanofibrous layers from polymeric solutions.

Biodegradation of electrospun polymeric especially PCL nanofibers are nowadays widely studied topics [9], which can be observed by different methods focused on the study of changes in the internal structure 
of nanofibers and also on morphological changes. This paper presents the observation of morphological changes in enzymatically catalysed degradation using a scanning electron microscope and changes in the internal arrangement unconventionally using the solid state NMR method.

\section{MATERIALS AND METHODS}

\subsection{Materials}

PCL 45 (Mw $45000 \mathrm{~g} \cdot \mathrm{mol}^{-1}$; Merck, Germany) was use for preparation of micro/nanofiber layers. A mixed solvent was used consisting of chloroform and ethanol (Penta, Czech Republic) in a ratio of 8:2 by weight. For enzymatic degradation of nanofibers, was used Lipase form Pseudomonas cepacia (specific activity $30 \geq \mathrm{U} \cdot \mathrm{mg}^{-1}$; Merck, Germany). Sodium azide $\left(\mathrm{NaN}_{3}\right)$ was obtained from Merck (Germany).

\subsection{Nanofibrous materials preparation}

Mikro/nanofibrous layers were electrospun from $16 \mathrm{wt} \%$ solutions of PCL 45. An appropriate amount of polymer was added to the mixed solvent and stirred at room temperature until the polymer was completely dissolved. Materials were prepared using electrospinning technology (Nanospider ${ }^{\mathrm{TM}}$ 1WS500U, Elmarco, Czech Republic). The prepared polymer solutions were electrospun at humidity $50 \%$ and temperature $22{ }^{\circ} \mathrm{C}$. The applied voltage was $-10 \mathrm{kV}$ (collector) and $+40 \mathrm{kV}$ (spinning string). The electrode distance was $180 \mathrm{~mm}$, the EMW speed was $450 \mathrm{~mm} / \mathrm{sec}$ and the rewinding speed was $30 \mathrm{~mm} / \mathrm{min}$. The diameter of the string was $0.4 \mathrm{~mm}$ and the size of the hole was $0.7 \mathrm{~mm}$. After that were materials stored at $4{ }^{\circ} \mathrm{C}$ at fridge.

Prepared materials were cut to testing samples and sterilized by means of Anprolene AN-74i (Anprolene; Great Britain) according standard (ČSN EN ISO 11135) applying a low-temperature cycle (at room temperature; 12 hours), then were samples ventilated for 1 week at room temperature.

\subsection{Enzymatic degradation}

For the degradation tests, the electrospun layers $\left(30 \mathrm{~g}^{-2}\right)$ were cut into small samples $(n=10+2$ negative control (NC) for testing day; weight of each sample $50 \pm 5 \mathrm{mg}$ ) and placed into $5 \mathrm{ml}$ vials and sterilized. (it was mentioned above). Enzymatic degradation was carried out at $37{ }^{\circ} \mathrm{C}$ in phosphate buffer solution (PBS with $0.02 \% \mathrm{NaN}_{3}, \mathrm{pH} 7.4$ ) to simulate biological fluids. These solutions contained $5 \mathrm{ml} \mathrm{PBS}+0.02 \% \mathrm{NaN}_{3}$ along with enzyme Lipase $\left(5 \mathrm{U} \cdot \mathrm{ml}^{-1}\right)$; for $\mathrm{NC}$ was prepared only pure buffer solution. PBS solution with enzymes was changed every day, at the same time 10 samples replicates and 2 NCs were removed, washed twice with distilled water and dried at room temperature a week before further investigation.

\subsection{Morphological analysis}

Morphological analysis was performed by scanning electron microscopy (Vega Tescan 3, Tescan, Czech Republic) after $10 \mathrm{~nm}$ of gold sputter coating (Quorum Q50ES, Quorum Technologies, Great Britain). Samples were analysed at an accelerating voltage of $20 \mathrm{kV}$. The average diameter and the diameter distribution were evaluated using Image $\mathrm{J}$ (300 randomly measured value from 4-5 images per each material).

\subsection{Weight loss analysis}

After properly drying samples, were immediately weighed using a digital balance (PA224C four-range analytical balance, Ohaus, Switzerland). To determine the percentage weight loss, weights of samples before and after degradation were determined and then subjected to calculation by Eq. (1). Four replicate samples were prepared and the values were averaged.

$w_{\text {loss }}=\frac{w_{b}-w_{a}}{w_{b}} \cdot 100$ 
where:
Wloss - weight loss of samples during the degradation (\%)
$w_{b}$ - dry weight before degradation $(\mathrm{mg})$
$W_{a-}$ dry weight after degradation $(\mathrm{mg})$

\subsection{SSNMR}

Solid-state NMR (ssNMR) spectra were collected using a $500 \mathrm{MHz}$ Bruker Avance III HD NMR spectrometer $(\mathrm{B} 0=11.7 \mathrm{~T})$ at Larmor frequency $\mathrm{v}(13 \mathrm{C})=125.833 \mathrm{MHz}$ using a double-resonance 3.2-mm magic angle spinning (MAS) probe. All MAS NMR experiments were recorded at a $20 \mathrm{kHz}$ spinning speed. The number of scans collected for each 13C MAS NMR spectrum was 1024 at recycle delays $10 \mathrm{~s}$. In case of 13C MAS NMR experiment, SPINAL64 decoupling sequence was applied for suppression of strong dipolar interactions. The $13 \mathrm{C}$ chemical shift was calibrated using glycine (13C: $176.03 \mathrm{ppm}$-high field signal). All dried samples were packed and kept in $\mathrm{ZrO} 2$ rotors.

\section{RESULTS AND DISCUSSION}

Crystallinity of PCL nanofibers during enzyme-catalysed degradation was studied. Due to the enzymatically catalysed degradation of polyester nanofibrous materials, changes in the fibber structure occur (see Figure 1). These changes are evident from electron microscopy images; according to available sources, there is, among other things, a change in the crystal structure of the polymer. Nanostructuralization of the surface is evident, which is probably due to the recrystallization of macromolecules during degradation (the macromolecules are broken down, the release of soluble degradation products is created and this creates free space and changes the character of interacting molecules). The experiment was focused on the analysis of the crystallinity of nanofibrous materials from PCL during enzymatically catalysed degradation. Degradation was catalysed by lipase from Pseudomonas cepacia, degradation was monitored by evaluating weight-loss (see Figure 2) and morphology.
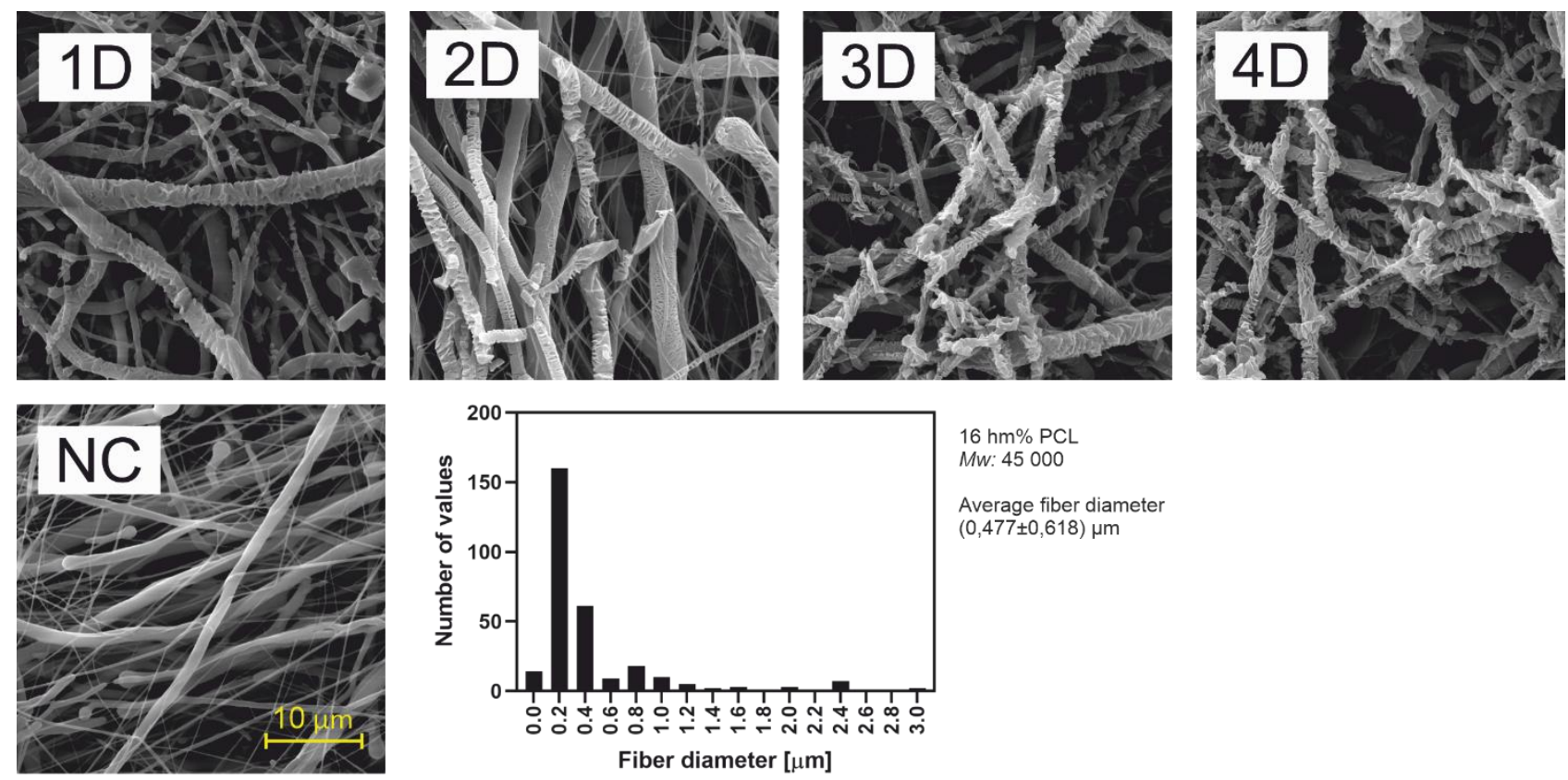

Figure 1 SEM images of PCL electrospun nanofibers capturing test PCL 45 samples after 1, 2, 3 and 4 days of degradation experiment in comparison with negative controls (NC). Scale 10 micrometres 


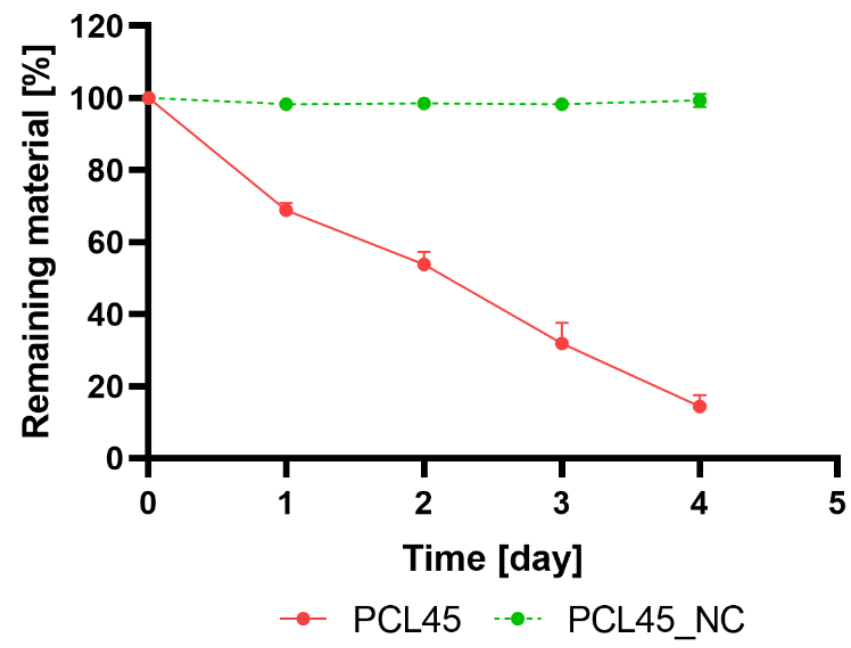

Figure 2 Graph of enzymatic degradation process of PCL 45 samples by Lipase from Pseudomonas cepacia. Weight loss or remaining material during enzymatic degradation process ( 1 - 4 days) is represented by red line in comparison of negative control (material without enzyme solution) represented by green line.

After 2 days was remaining material $(53,75 \pm 3,59) \%$, at the end of experiment it was $(14,40 \pm 3,11) \%$.

The ${ }^{13} \mathrm{C}$ MAS NMR spectroscopy was used for investigation of enzymatic degradation processes of polycaprolactone in range of four days, see Figure 3.

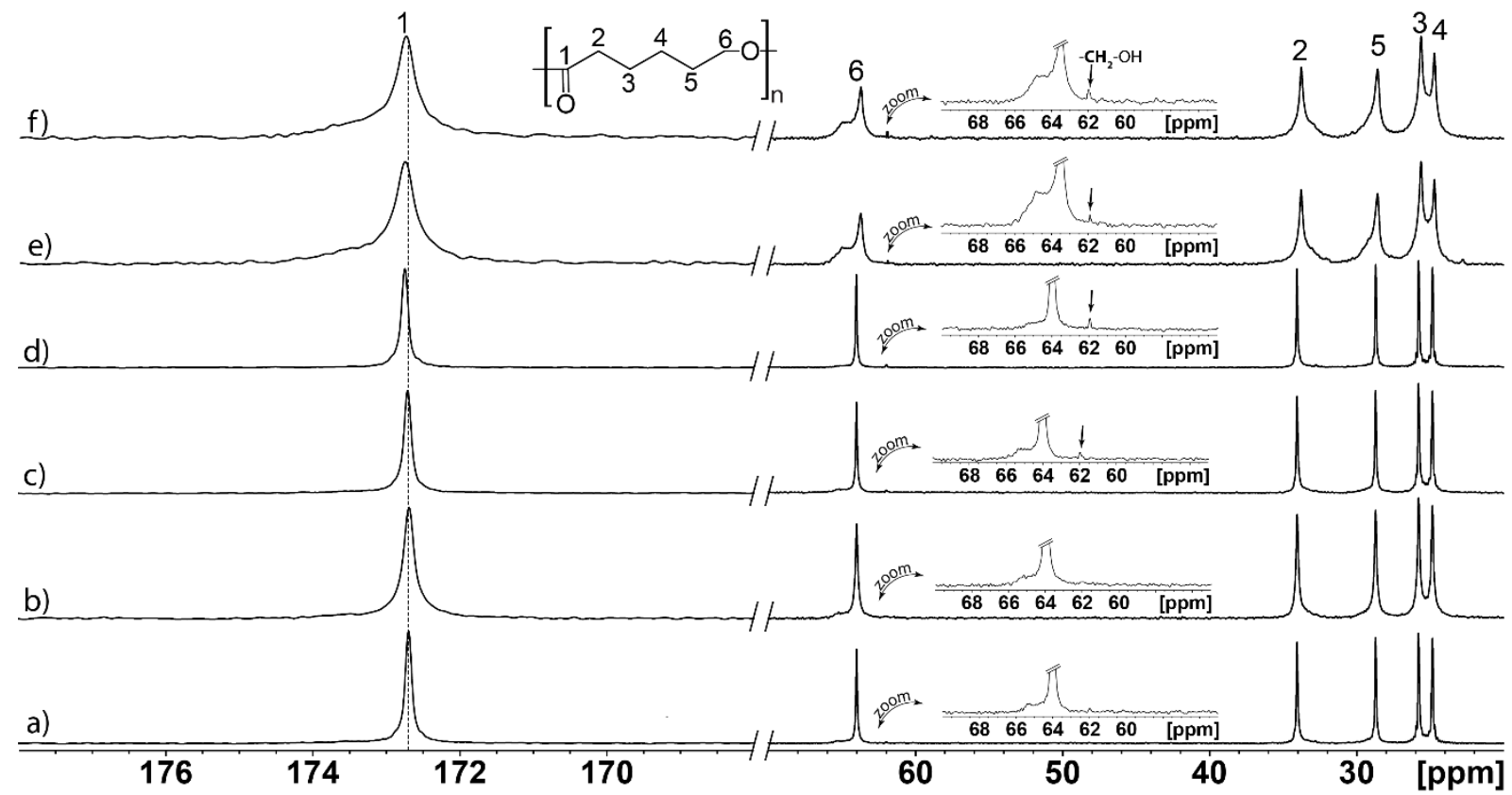

Figure 3 Experimental 13C MAS NMR spectra of investigated polycaprolactones (PCL 45) at distinct degradation times - a) fresh, b) control sample, c) one day degraded, d) two days degraded, e) three days degraded and f) four days degraded.

From comparison of ${ }^{13} \mathrm{C}$ MAS NMR spectra of fresh and control sample (Figure 2) and b)) it is evident that all detected signals of control sample are slightly broadened. However, no changes in signal shift or new spectral line(s) were detected. This signal broadening can be result of moderate structural differences. Control sample can be defined as a material with a higher degree of disorder. (In other words, the crystallinity of control sample is lower as compare to fresh sample; signal broadening is maybe caused by swelling of sample). 
In case of enzymatic degradation, the changes in ${ }^{13} \mathrm{C}$ MAS NMR spectra are more significant (compare spectra in Figure 1 a-f)). Firstly, one new small peak, at ca. 62 ppm, was observed in all treated systems (Figure $1 \mathrm{c}-\mathrm{f})$ ). This peak was attributed to methylene groups neighbouring with hydroxyl groups $\left(-\mathrm{CH}_{2}-\mathrm{OH}\right)$ at the end of macromolecular chains. Their slightly increasing intensity suggests some degree of depolymerization process. Moreover, the structural changes induced by enzymatic degradation are clearly visible in case of three and four days treated samples in ${ }^{13} \mathrm{C}$ MAS NMR spectra (Figure $\mathbf{1}$ e) and f). The significant broadening of all detected signals and appearance of new relatively broad signal at $65 \mathrm{ppm}$ is evident in Figure 2. These changes in ${ }^{13} \mathrm{C}$ MAS NMR spectra suggest a formation of disorder/amorphous phase after three/four days of enzymatic treatment. Furthermore, small change was observed in case of carbonyl carbons $(\mathrm{C}=\mathrm{O})$, see Figure 2. This slight downfield shift is caused by formation of stronger inter- or intra- molecular bond(s) $[10,11]$.

\title{
4. CONCLUSION
}

Study of biodegradation process is very complex phenomenon not only for nanofibrous materials. PCL electrospun nanofibers showed interesting morphological and internal structure changes as it is obvious from SEM images and SSNMR spectra. Nanostructulization of the surface is observed, probably due to recrystallization of macromolecules during degradation. Penetration of water (PBS) into the polymer caused hydrolytic degradation, when amorphous domains are attacked primary and it probably cause a higher chain flexibility in comparison of crystalline regions. [12,13] Than is possible observed formation of stronger molecular bonds and possibly increasing of crystallinity. The result interpretation is not simple and there is necessary to study by these method different biodegradable materials and to compare them with other analytical methods.

\section{ACKNOWLEDGEMENTS}

\begin{abstract}
Authors thank for the financial support of the grant "Study of physical networks in polymer materials" of the Technical University of Liberec Grant Program „PURE“, No. PURE-2020-4007.
\end{abstract}

\section{REFERENCES}

[1] BAJI, A., MAI, Y.-W., WONG, S.-C., ABTAHI, M., CHEN, A P. Electrospinning of polymer nanofibers: Effects on oriented morphology, structures and tensile properties. Composites Science and Technology. [online]. 2010, vol. 70, no. 5, pp. 703-718. Available from: https://doi.org/10.1016/j.compscitech.2010.01.010.

[2] LOWERY, J. L., DATTA, N., RUTLEDGE, A G. C. Effect of fiber diameter, pore size and seeding method on growth of human dermal fibroblasts in electrospun poly( $\varepsilon$-caprolactone) fibrous mats. Biomaterials. [online]. 2021, vol. 31, no. 3, pp. 491-504. Available from: https://doi.org/10.1016/i.biomaterials.2009.09.072.

[3] VAN DER SCHUEREN, L., DE SCHOENMAKER, B., KALAOGLU, Ö. I., DE CLERCK, A K. An alternative solvent system for the steady state electrospinning of polycaprolactone. European Polymer Journal. [online]. 2011, vol. 47, no. 6, pp. 1256-1263. Available from: https://doi.org/10.1016/j.eurpolymj.2011.02.025.

[4] WANG, X., ZHAO, H., TURNG, L.-S., LI, A Q. Crystalline Morphology of Electrospun Poly( $\varepsilon$-caprolactone) (PCL) Nanofibers. Ind. Eng. Chem. Res. [online]. 2013, vol. 52, no. 13, pp. 4939-4949. Available from: https://doi.org/10.1021/ie302185e.

[5] NAYAK, R., PADHYE, R., KYRATZIS, I. L., TRUONG, Y. B., ARNOLD, A L. Recent advances in nanofibre fabrication techniques. Textile Research Journal. [online]. 2012, vol. 82, no. 2, pp. 129-147. Available from: https://doi.org/10.1177/0040517511424524.

[6] A. BARHOUM, K. PAL, H. RAHIER, H. ULUDAG, I. S. KIM, A M. BECHELANY, „Nanofibers as new-generation materials: From spinning and nano-spinning fabrication techniques to emerging applications", Applied Materials Today. 2019, vol. 17, pp. 1-35. Available from: https://doi.org/10.1016/j.apmt.2019.06.015. 
[7] POKORNY, P. et al., Effective AC needleless and collectorless electrospinning for yarn production. Phys. Chem. Chem. Phys. [online]. 2014, vol. 16, no. 48, pp. 26816-26822. Available from: https://doi.org/10.1039/C4CP04346D.

[8] VALTERA, J. et al. Fabrication of dual-functional composite yarns with a nanofibrous envelope using high throughput AC needleless and collectorless electrospinning. Sci Rep. [online]. 2019, vol. 9, no. 1, p. 1801. Available from: https://doi.org/10.1038/s41598-019-38557-z.

[9] DONG, Y., LIAO, S., NGIAM, M., CHAN, C. K., RAMAKRISHNA, A S. Degradation Behaviors of Electrospun Resorbable Polyester Nanofibers. Tissue Engineering Part B: Reviews. [online]. 2009, vol. 15, vol. 3, pp. 333351. Available from: https://doi.org/10.1089/ten.teb.2008.0619.

[10] MACIEL, G. E., RUBEN, A G. C. Solvent Effects on the C ${ }^{13}$ Chemical Shift of the Carbonyl Group of Acetone. J. Am. Chem. Soc. [online]. 1963, vol. 85, no. 23, pp. 3903-3904. Available from: https://doi.org/10.1021/ja00906a049.

[11] TAKEGOSHI, K., NAITO, A., MCDOWELL, A C. A. Intermolecular hydrogen-bonding effects on the 13C NMR shielding tensor of the carbonyl carbon nucleus in a single crystal of dimedone. Journal of Magnetic Resonance (1969). [online]. 1985, vol. 65, no. 1, pp. 34-42. Available from: https://doi.org/10.1016/0022-2364(85)90373-7.

[12] NATU, M. V., DE SOUSA, H. C., GIL, A M. H. Influence of polymer processing technique on long term degradation of poly( $\varepsilon$-caprolactone) constructs. Polymer Degradation and Stability. [online]. 2013, vol. 98, no. 1, pp. 44-51. Available from: https://doi.org/10.1016/j.polymdegradstab.2012.10.030.

[13] ANTHEUNIS, H., VAN DER MEER, J.-C., DE GEUS, M., HEISE, A., KONING, A C. E. Autocatalytic Equation Describing the Change in Molecular Weight during Hydrolytic Degradation of Aliphatic Polyesters.

Biomacromolecules. [online]. 2010, vol. 11, no. 4, pp. 1118-1124. Available from: https://doi.org/10.1021/bm100125b. 